\title{
LIFE CYCLE ASSESSMENT OF SILICON ALLOY-BASED LITHIUM-ION BATTERY FOR ELECTRIC VEHICLES
}

\author{
MAEVA PHILIPPOT ${ }^{1,2}$, JELLE SMEKENS $^{1,2}$, JOERI VAN MIERLO $^{1,2} \&$ MAARTEN MESSAGIE $^{1,2}$ \\ ${ }^{1}$ ETEC Department \& MOBI Research Group, Vrije Universiteit Brussel (VUB), Belgium \\ ${ }^{2}$ Flanders Make, Belgium
}

\begin{abstract}
Battery Electric Vehicles (BEV) are seen as a solution for cleaner mobility, due to their ability to reduce air emissions in cities. Batteries are key components that have a large influence on performances of EVs. Energy density is an important requirement from automotive industry, therefore the goal of this study is to assess the impact of a traction battery with new cells containing a high voltage NMC cathode and silicon alloy based anode on climate change. Silicon is a promising material for traction batteries, considering its high energy density. The scope of the paper is the manufacturing. This study uses the life cycle assessment method. Setting coherent system boundaries and functional units is essential and literature regarding these choices is reviewed. Site-specific data from industrial partners is collected as much as possible. The uncertainty of the results is then assessed thanks to a Monte Carlo simulation. The main contributor to climate change is cell manufacturing due to the use of fossil resources for electricity generation. The next big contributor is the cathode paste, half of the cathode paste emissions occurring in the nickel sulphate manufacturing. Note that nickel sulphate is the main precursor in the cathode. Substrates, electrolytes and separators do not represent high shares of emissions, even though they represent almost $40 \%$ of the cell mass. To evaluate the robustness of the conclusions, a sensitivity analysis is performed. Today, most of batteries are manufactured in China and the European Commission is pushing toward a more local production. The sensitivity of the results is tested by replacing the original mix by the Chinese average mix and by renewable energy sources. In conclusion, manufacturing in Europe can reduce the impact on climate change and using hydropower and/or photovoltaic panels can even improve the environmental performances of manufacturing of this battery. Keywords: battery manufacturing, electric vehicle, life cycle assessment, GHG emissions, silicon lithium ion battery, NMC battery, silicon anode, Cradle to Gate.
\end{abstract}

\section{INTRODUCTION}

There is a growing concern about climate change and transport sector. It seems that low carbon mobility can be reached with electric and hybrid vehicles charged with electricity with low GHG (Greenhouse Gas) emissions [1]. Electric powertrains are efficient during use stage but manufacturing of batteries can be energy intensive. It is therefore interesting to focus on GHG emissions of battery manufacturing. This can be performed through a Life Cycle Assessment (LCA), which is a recognized and standardized method to assess environmental impacts of products or services [2].

Several chemistries for batteries are commercially available today and others are still in development [3]. Increasing the energy density of traction batteries is possible using new materials such as silicon for anode active material [4]. Li et al. [5] studied the LCA of a lithium ion battery with a silicon nanowires anode and NMC 111 cathode (lithium Nickel Manganese Cobalt oxide cathode that contains ca. the same amount of nickel, manganese and cobalt). These authors reported that this new anode generated most of the GHG emissions of the battery manufacturing. In our study, nevertheless, the anode is composed of siliconbased alloy, not on nanowires. We focus expressly on manufacturing stage instead of considering also the use stage which might be more difficult to evaluate with new battery technologies that have not yet reached maturity. 
Environmental performances of LIBs (Lithium Ion Battery) have been the subject of research for several years. Peters et al. [6] found 79 studies on lithium ion batteries and 34 on traction batteries between 2010 and 2016. Among all these publications, the differences in goal and scope bring different boundaries, FUs (Functional Unit) and modelling approaches. There are mainly 4 types of FUs used in literature: measured in battery weight, in energy content, in delivered energy, and in distance. It should be noted, though, that FUs of the same type are not necessarily equivalent and that comparing LCAs that have apparently the same FU is not straight forward. For instance, if the FU is measured in distance, the parameters of the car such as power electronics efficiency and the drivetrain must be the same for the results to be comparable. When focusing on manufacturing, it is more suitable to use a FU based on characteristics of the battery that are not dependent of the use stage.

Fossil fuels generate most of the impact on climate change whether they are used to generate electricity for use stage or for manufacturing [6]. To have robust results, sensitivity should be addressed [2] in order to understand the relative importance of parameters. Electricity mix is often a relevant parameter assessed during sensitivity analysis [7]-[9]. Reliability can also be attained thanks to a range-based analysis [10] or uncertainty quantification [7], [11].

This manuscript begins with the methodology in Section 2, where the first step of the ISO standard, goal and scope definition, is addressed. In Section 3, the inventory is detailed. Section 4 includes the results of the impact assessment, interpretation, sensitivity and uncertainty analysis. Finally, Section 5 describes the conclusions of this research.

\section{METHODOLOGY}

Life Cycle Assessment (LCA) is a tool that assesses environmental performance all along the life cycle of a product: from raw material extraction to recycling and final disposal. LCA has been standardized [2] and the procedure is divided into 4 steps: goal and scope definition, inventory analysis, impact assessment and interpretation. Definition of the goal and scope should address the context, the intended audience, the objectives, the system boundaries, the functional unit and the modelling choices. Afterwards all relevant material and energy flows are inventoried. To establish a good inventory, the quality of the data is essential. The next step is translating inputs and outputs of elementary flows into impact indicators and interpret the results.

\subsection{Goal and scope definition}

We developed a new cell technology for NMC traction batteries with high capacity anode, high voltage cathode and new electrolytes. This study will then focus on the manufacturing of the developed technology in Europe. The objective of this study is to answer four questions: 1) What is the influence of nickel content on GHG (Greenhouse Gas) emissions of manufacturing this cell and a pack containing these cells? 2) What is the influence of silicon based anode on GHG emissions of manufacturing this cell and a pack containing these cells? 3) Is the manufacturing of this new battery a good alternative to current batteries in terms of GHG emissions? and 4) How can the manufacturing of this new technology achieve lower GHG emissions?

To answer these questions, the manuscript considers raw materials production, transport and manufacturing of the cells and battery pack. It is a Cradle to Gate $(\mathrm{CtG})$ analysis. First, we focus on the cell manufacturing ( $\mathrm{CtG}$ Cell in Fig. 1) and in a second time, on the whole battery pack manufacturing (CtG Battery in Fig. 1), including battery housing, cooling system, Battery Management System (BMS) and module packaging. The battery has been 


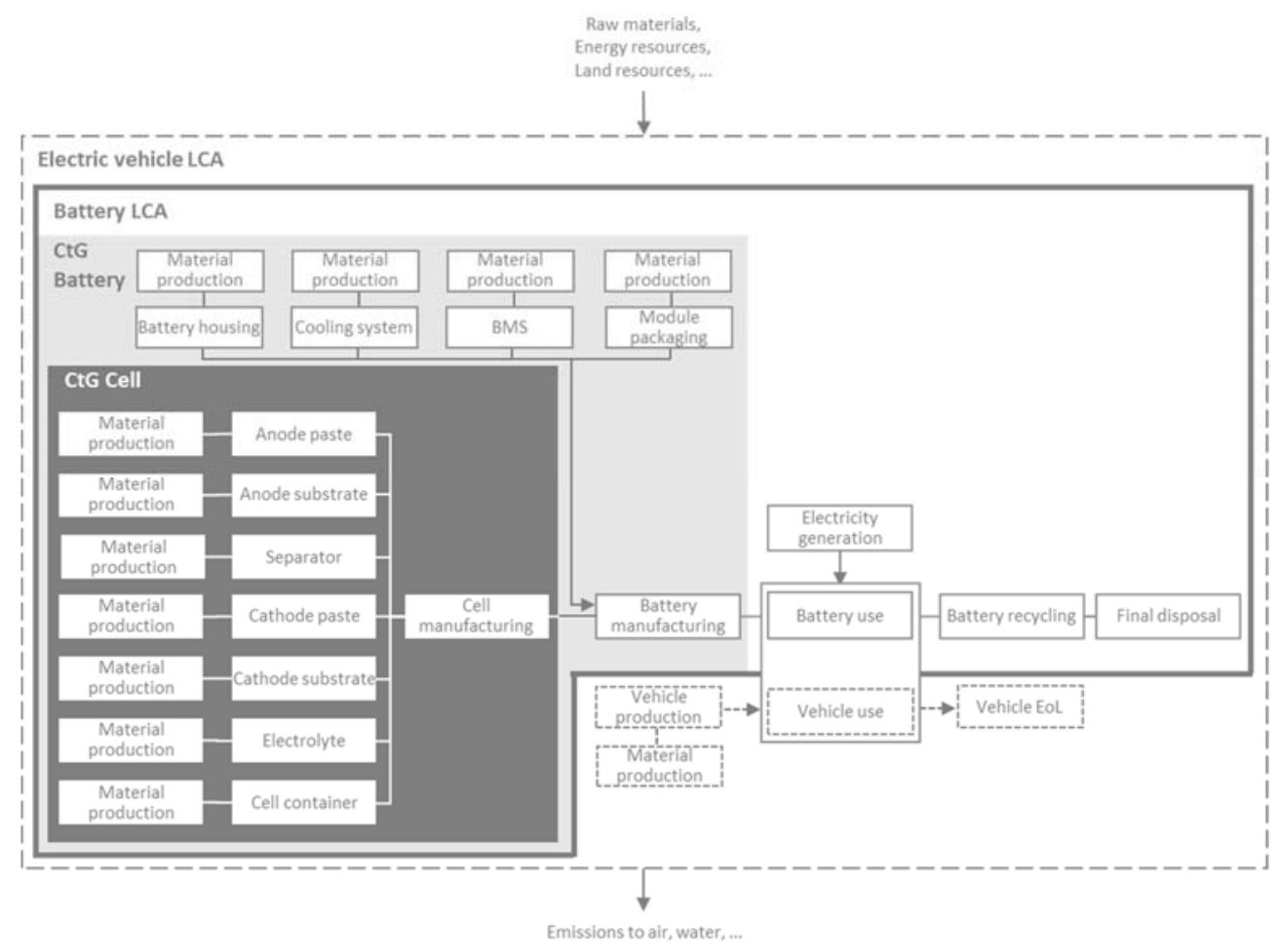

Figure 1: System boundaries of battery LCA.

assessed using attributional process based LCA. The Functional Unit (FU) is the quantified performance of the studied system that serves as the reference unit to which all the inventory and impact assessment are reported. The FU is $1 \mathrm{kWh}$ energy content of a cell or of a 30kWh battery pack.

\subsection{Inventory and data quality}

The important processes in battery manufacturing LCA are: production of the electrodes, of the electrolyte, of the separator, of the case, of the BMS and assembly. The best data quality is obtained using site-specific manufacturing data. This kind of information has therefore been gathered as much as possible from project partners for foreground processes. For background processes, such as raw material extractions and electricity generation, the database Ecoinvent 3.3 is used. The modelling is carried out with the LCA software Simapro 8.4. The data quality of the project will be assessed using a Pedigree matrix [12].

\subsection{Impact assessment and interpretation}

GHG emissions lead to climate change that may have a broad range of impacts on ecosystems. GHG exhibit different behavior over time, the characterization factors depend on the chosen time-horizon. The time horizon for this study is 100 years and the characterization factors are those of the IPCC 2013 method V1.03. 


\subsection{Sensitivity and uncertainty analysis}

Sensitivity of the results to key parameters and uncertainty need to be assessed to better understand the reliability of the results. In this study, sensitivity analysis is performed by assessing the influence of silicon manufacturing and energy source for manufacturing on the results. This analysis helps in evaluating the robustness of the conclusions. After assessing the data quality, the uncertainty is quantified through a Monte Carlo simulation, assuming a lognormal distribution for all gathered data. 1000 runs will be performed. This uncertainty quantification focuses on parameter uncertainty.

\section{LIFE CYCLE INVENTORY}

\subsection{Battery characteristics}

The new cells developed are prismatic cells composed of NMC 622 cathode and silicon alloy based anode, in an aluminum hard case. Table 1 shows the inventory of the cells. The higher energy density of silicon compared to graphite, usually used in battery anodes, allows to decrease the quantity of anode paste [4]. The cycle life expectation for such a chemistry is 1000 cycles $(100 \% \mathrm{DoD}, \mathrm{C} / 3)$.

A module is composed of 12 cells and a pack is composed of 24 modules which leads to a $30-\mathrm{kWh}$ pack (Table 2). The energy density is increased by $15 \%$ compared to the same battery with graphite anode. This new technology in a pouch cell would have an energy density of almost $240 \mathrm{Wh} / \mathrm{kg}$ which is at the upper limit of today's LIBs [13].

The module pack has been designed and the total mass of the battery is calculated assuming that the cells represent $70 \%$ of the total mass (Table 3).

Table 1: Life cycle inventory of the silicon based cell.

\begin{tabular}{|l|l|}
\hline Component & $\% \mathrm{w}$ \\
\hline Positive electrode paste & $28 \%$ \\
\hline Negative electrode paste & $12 \%$ \\
\hline Separator & $5 \%$ \\
\hline Substrate, positive electrode & $5 \%$ \\
\hline Substrate, negative electrode & $9 \%$ \\
\hline Electrolyte & $20 \%$ \\
\hline Cell container & $21 \%$ \\
\hline
\end{tabular}

Table 2: Battery characteristics.

\begin{tabular}{|l|l|}
\hline Cell weight $[\mathrm{kg}]$ & 0.55 \\
\hline Module Energy $[\mathrm{kWh}]$ & 1.24 \\
\hline Module Weight $[\mathrm{kg}]$ & 8.22 \\
\hline Pack Weight $[\mathrm{kg}]$ & 226.3 \\
\hline Pack Energy $[\mathrm{kWh}]$ & 30 \\
\hline Energy density $[\mathrm{Wh} / \mathrm{kg}]$ & 131 \\
\hline Cell voltage $[\mathrm{V}]$ & 3.6 \\
\hline
\end{tabular}


Table 3: Mass repartition of the battery pack.

\begin{tabular}{|l|l|}
\hline Component & $\% \mathrm{w}$ \\
\hline Cells & $70 \%$ \\
\hline Module packaging & $17 \%$ \\
\hline Battery tray and battery retention & $6 \%$ \\
\hline BMS & $5 \%$ \\
\hline Cooling system & $2 \%$ \\
\hline
\end{tabular}

\subsection{Manufacturing}

\subsubsection{Cell and pack manufacturing process}

The facility for cell and battery manufacturing is located in Germany. The manufacturing process is similar for different lithium ion battery chemistries: mixing electrode pastes, coating on current collectors, drying, stacking, filling of electrolyte, sealing and testing. Several steps of this process happen in dry rooms that are known to be energy intensive. The cells are manufactured in a pilot scale facility but no data was available on energy consumption. Sanfélix [14] gathered data from a cell manufacturer and found that cell assembly requires an average of $18 \mathrm{kWh} / \mathrm{kg}$ of cell (assuming that all heating and cooling is produced by electricity, assumption made by the manufacturer). The module and battery pack manufacturing consists of assembly and welding, and also testing of the packs. The energy required for assembly is evaluated to $4 \mathrm{E}-4 \mathrm{kWh} / \mathrm{kg}$ [8]. This energy is low, compared to the manufacturing energy of the cells, as the battery assembly is mainly performed manually. The battery pack quality testing and validation consumes $6.4 \mathrm{E}-3 \mathrm{kWh} / \mathrm{kg}[5]$.

\subsubsection{Cathode}

In the NMC family, the proportion of nickel, manganese and cobalt have an impact on battery properties: more nickel results in a higher capacity, while higher manganese content results in a higher safety and higher cobalt results in a better reversibility. The cathode active material is NMC622 containing ca. $60 \%$ nickel, ca. 20\% manganese and ca. $20 \%$ cobalt. Considering the costs, an NMC 622 battery with silicon alloy-based anode could cost $30 \%$ less than an NMC 622 battery with graphite anode [3]. As cobalt is considered a critical raw material for Europe [15], decreasing its use in batteries is interesting to decrease dependence on foreign suppliers. The oxide is manufactured in China and in Korea. Data for the active material is gathered directly from the manufacturer. During the mixing, N-methyl-2pyrrolidone (NMP) is added as a solvent and we assume that all this solvent evaporates during drying. The cathode paste is coated on a $20 \mu \mathrm{m}$ thick aluminum foil.

\subsubsection{Anode}

Silicon has a higher energy density than graphite generally used in LIB anodes $(3579 \mathrm{mAh} / \mathrm{g}$ for silicon and $372 \mathrm{mAh} / \mathrm{g}$ for graphite [4]). The energy density increases with increasing silicon alloy content, but cycling stability is challenged due to side reactions and volume changes. Natural graphite is considered as a critical raw material for Europe [15] and it cannot be recovered through battery recycling. Reducing the quantity of natural graphite in batteries is therefore interesting from the point of view of supply risk. The silicon alloy content in the anode paste is $27 \%$ and graphite only $16 \%$, much lower than other NMC batteries [8], [16].

The silicon alloy contains silicon, iron and carbon according to [17]. The silicon powder used in the alloy manufacturing is pure at $99.9 \%$. In the Ecoinvent database, the purity of the 
metallurgical grade silicon lies between $98.5 \%$ and $99.5 \%$ [18]. Using metallurgical grade might underestimate environmental impacts of the material. Nevertheless, the solar grade impurity tolerances are not greater than $0.01 \mathrm{ppmw}$ (parts per million weight), choosing this dataset should increase environmental impacts of the silicon alloy; this choice will be tested during sensitivity analysis.

The anode slurry is aqueous, no NMP is used. Zackrisson et al. [19] showed that waterbased slurries for cathode and anode have lower GHG emissions than NMP containing slurries. This slurry is coated on a $10 \mu \mathrm{m}$ thick copper foil.

\subsubsection{Electrolyte}

The electrolyte is a mixture of $\mathrm{LiPF}_{6}$ and lithium 4,5-dicyano-2-(trifluoromethyl) imidazolide (LiTDI) in solvents. LiTDI has several advantages over $\mathrm{LiPF}_{6}$ : thermal stability up to $250^{\circ} \mathrm{C}$, protection of aluminum against corrosion, and oxidation stability at $4.6 \mathrm{~V}$ versus $\mathrm{Li}+/ \mathrm{Li}$. With $\mathrm{LiMn}_{2} \mathrm{O}_{4}$ cathode, this salt produces good cycling behaviour and good power capability. Nevertheless, this LiTDI has a lower conductivity which can be optimized with a mixture of several carbonates. $\mathrm{LiPF}_{6}$ is modelled according to data provided by the manufacturer. The data for LiTDI manufacturing is confidential, the proxy used is the data for lithium bis (trifluoromethylsulfonyl) imide from [20]. According to the manufacturer, this is a good proxy.

\subsubsection{Separator, BMS, cell container, module, battery housing and cooling system}

The separator is a porous polymer layer placed between anode and cathode. It is a three layers separator modeled with data from Ecoinvent for plastics granulate and injection molding. The cell containers are aluminium hard case with aluminium and copper current collectors. Aluminium represents $70 \%$ of the mass of the container. The module packaging is composed at $54 \%$ of aluminium. The BMS, battery tray, battery retention and cooling system have not been designed in this project. Data from [8] is then scaled to the total mass of the battery obtained by considering that $70 \%$ of the total weight is composed of the cells.

\section{LIFE CYCLE IMPACT ASSESSMENT}

\subsection{Total impacts of manufacturing of the cells and of the battery pack}

The contribution of electrode pastes, separator, substrates, electrolyte, cell container and cell manufacturing are shown on the left column in Fig. 2. Each process (except cell manufacturing) that contributes to more than $2 \%$ of the total GHG emissions is detailed on the middle column. The right column represents the mass composition of the cell.

The main contributor is the manufacturing stage of the cell, which mainly consists of electricity from Germany. We do not have details on energy consumption during the manufacturing stage, but it is reasonable to assume that the drying is the most intensive process. The next big contributor is the cathode paste, $40 \%$ of the cathode paste emissions occurring in the nickel sulfate manufacturing process. Note that nickel sulfate is the main precursor as the active material is NMC 622 and the ore extraction is energy intensive. The anode paste emits ca. 6 times less GHG than the cathode paste but the aircraft transport of the silicon alloy contributes to $20 \%$ of the anode paste impact. In the anode paste, the US electricity mix shows a relatively high share, but energy intensity for the silicon alloy manufacturing is a data for lab scale. The silicon itself represents $24 \%$ of the anode paste emissions, in the sensitivity analysis, we will see how much higher this share is with a highergrade silicon. The aluminum cell container is also a significant contributor. Substrates, 
electrolyte and separator do not represent high shares of GHG emissions, even though they represent almost $40 \%$ of the mass share of the cell.

Considering the whole battery pack (Fig. 3), the $\mathrm{CtG}$ GHG emissions reach 163 $\mathrm{kgCO}_{2} \mathrm{eq} / \mathrm{kWh}$, calculated with IPCC 2013 method V1.03. Note that, if calculated with IPCC $2007 \mathrm{~V} \mathrm{1.02}$, the GHG emissions are $160 \mathrm{kgCO}_{2} \mathrm{eq} / \mathrm{kWh}$. The values found in [6] lie between $35 \mathrm{~kg} \mathrm{CO}$ eq $/ \mathrm{kWh}$ and $356 \mathrm{CO}_{2} \mathrm{eq} / \mathrm{kWh}$ for $\mathrm{NMC}$ batteries (mean value $160 \mathrm{~kg} \mathrm{CO}$ eq $/ \mathrm{kWh}$ ). Many of those values found in literature may be based on IPCC 2007.

Even at battery pack level, cell manufacturing and cathode paste are predominant on the impact on climate change. Nevertheless, the hard case is not negligible as it consists of aluminum. The high share of this component shows the energy intensity of aluminum processing. The emissions of the module and battery packaging mainly originate from the aluminum present in the module packaging.

\subsection{Sensitivity}

\subsubsection{Scenario analysis}

As previously mentioned, there is no silicon dataset in Ecoinvent that matches the requirements for the silicon alloy manufacturing. Metallurgical grade has been chosen for the

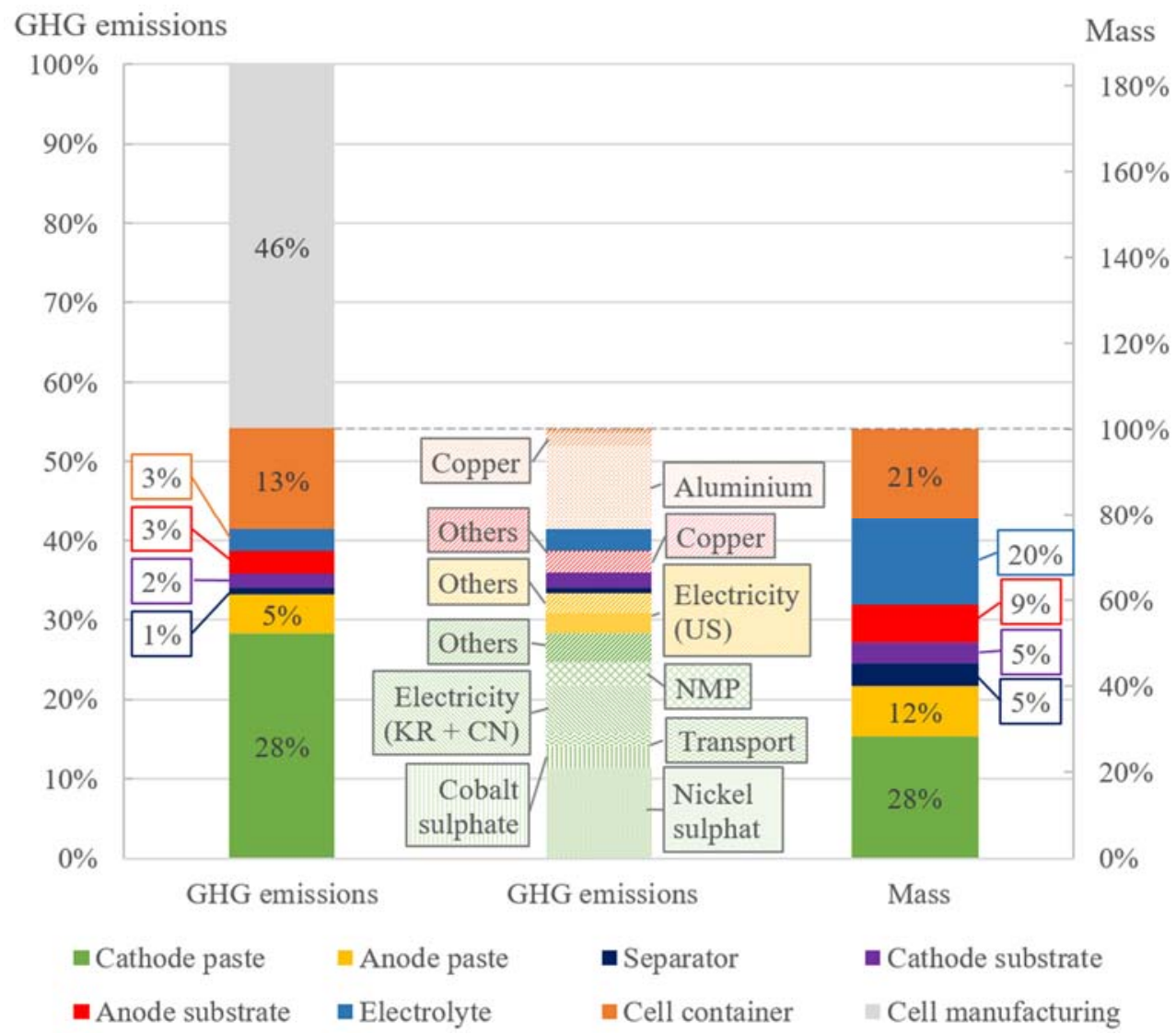

Figure 2: GHG emissions of manufacturing $1 \mathrm{kWh}$ energy content cell. 


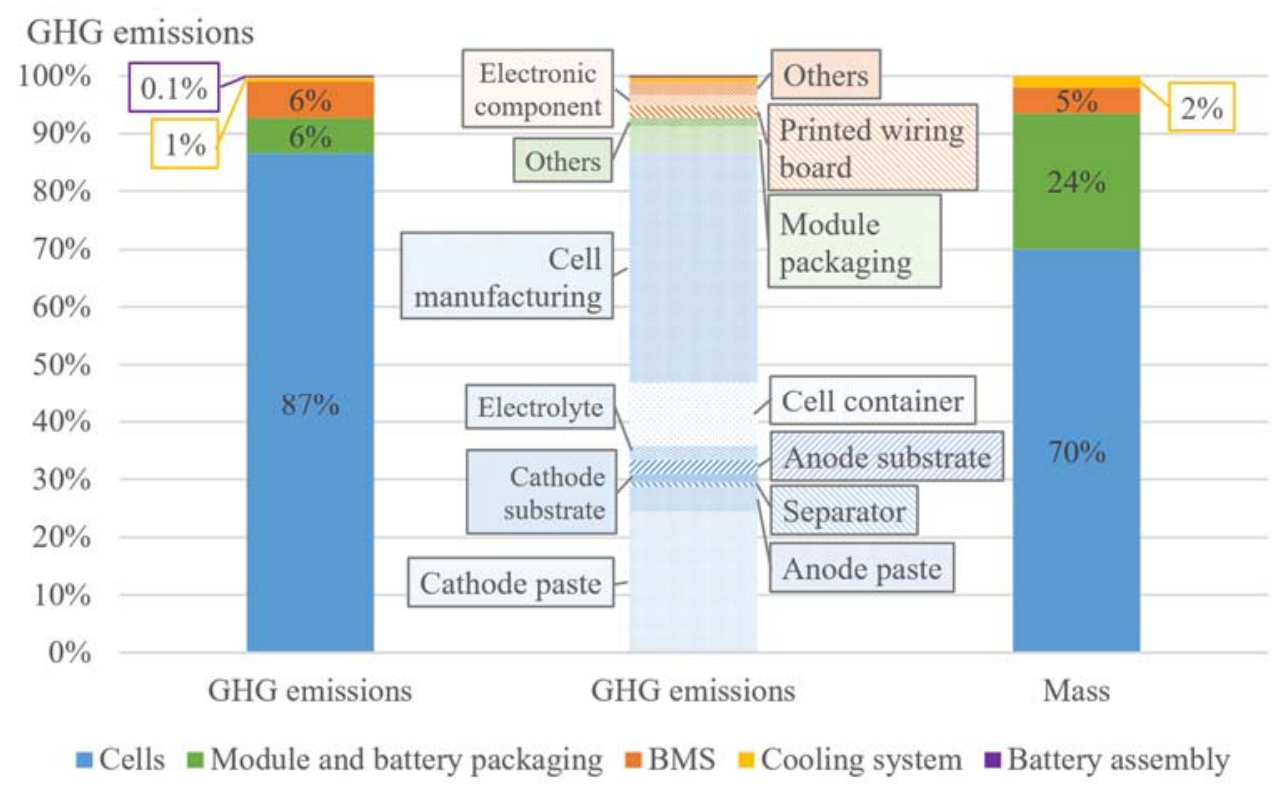

Figure 3: GHG emissions of manufacturing $1 \mathrm{kWh}$ energy content battery pack.

base case, and, according to [21], polysilicon solar grade is suitable for battery anodes. It is a metallurgical grade silicon that follows a modified Siemens process. The impact on climate change at the cell level is higher if the silicon is a solar grade, and the relative difference is $2.6 \%$.

The manufacturing facility of the cells and the battery is in Germany for the base case, where electricity generation is mainly based on fossil resources. Today, most of the battery are manufactured in China and the European Commission is pushing toward a more local production. In this section, the German electricity mix is then replaced by 2015 Chinese average, 2015 European average and 2015 Norwegian electricity mix. Norwegian electricity mix is chosen because it is based on renewable energy sources: hydropower $(95 \%)$. The manufacturing electricity will also be provided by photovoltaic panels $(100 \% \mathrm{PV}$ and $50 \%$ $\mathrm{PV}+50 \%$ German electricity mix) and wind turbines (100\% wind energy and $50 \%$ wind energy $+50 \%$ German electricity mix) to account for the intermittent nature of these energy sources.

Renewable energies allow to decrease the impact on climate change up to $37 \%$ (Fig. 4). Ellingsen et al. [8] found a decrease of more than $60 \%$ on the impact on climate change using electricity based on hydroelectric power for manufacturing.

\subsection{Uncertainty}

To quantify the uncertainty of the previous results, 1000 runs of a Monte Carlo simulation are performed and the distribution of the results is shown in Fig. 5. The 95\% confidence interval is $[140 ; 194] \mathrm{kgCO}_{2} \mathrm{eq} / \mathrm{kWh}$. The coefficient of variation, defined as the ratio of the standard deviation to the mean is $8 \%$. This coefficient of variation shows the reliability of the results of this study. 


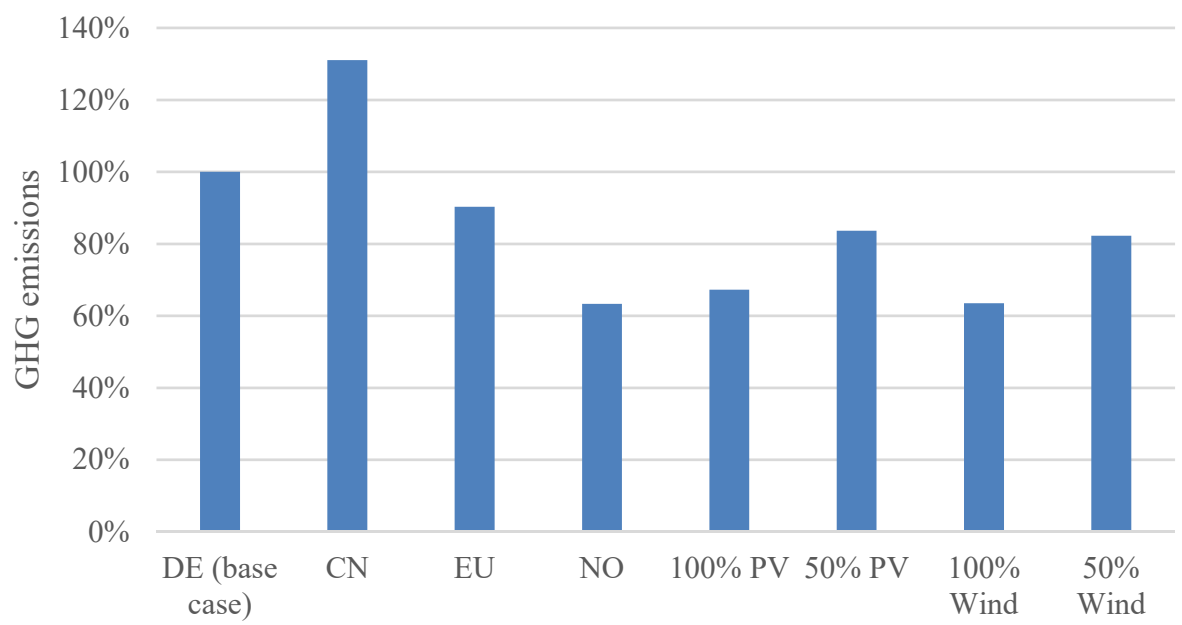

Figure 4: GHG emissions of the manufacturing of $1 \mathrm{kWh}$ battery pack with German electricity mix (DE), Chinese electricity mix $(\mathrm{CN})$, European average electricity mix (EU), only photovoltaic energy (100\% PV), half photovoltaic energy $(50 \%$ PV), only wind energy (100\% wind) and half wind energy (50\% wind).

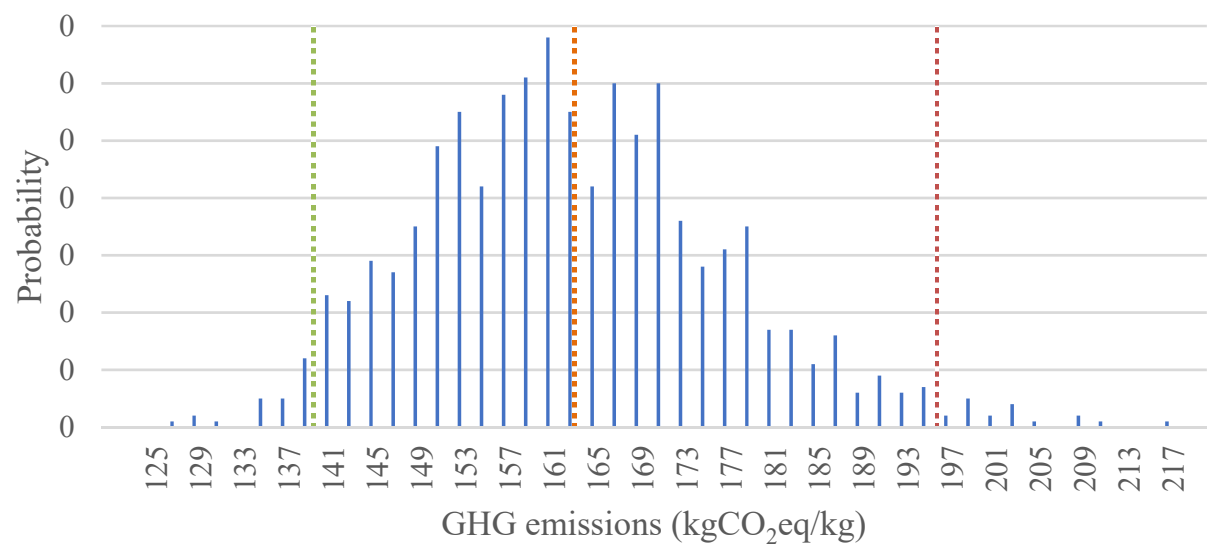

$=$ Mean $=$ Lower bound of the $95 \%$ confidence interval $=$ Upper bound of the $95 \%$ confidence interval

Figure 5: Distribution of GHG emissions of manufacturing $1 \mathrm{kWh}$ energy content pack.

\section{CONCLUSION}

Energy density of batteries is a key issue for automotive industry. Silicon is a promising material to increase this density. In this study, the GHG emissions of manufacturing an NMC battery with a silicon based anode are evaluated. The key parameters for environmental 
performances of this new battery pack are the energy consumption for cell manufacturing and the cathode paste materials.

Four questions were to be answered in the objectives. First, on a cell level, nickel is the material that contributes more to the impact on climate change, due to the energy intensiveness of its mining and refining process. Secondly, silicon has a smaller influence on the manufacturing GHG emissions of the cell. Thirdly, the manufacturing of this new cell technology seems to be a good alternative to current batteries. Lastly, it is even more true if the energy source includes renewable energy sources such as hydropower, solar energy or wind energy.

This study only focuses on manufacturing stage but as LCA has the power to assess the entire life cycle, with information on the use stage and the end of life, the new pack could be assessed.

\section{ACKNOWLEDGEMENTS}

This project has received funding from the European Union's Horizon 2020 research and innovation programme under grant agreements No 653531 and No 769935. We acknowledge Flanders Make for the support to our research group.

\section{REFERENCES}

[1] Nordelöf, A., Messagie, M., Tillman, A.M., Ljunggren Söderman, M. \& Van Mierlo J., Environmental impacts of hybrid, plug-in hybrid, and battery electric vehicleswhat can we learn from life cycle assessment? The International Journal of Life Cycle Assessment, 19(11), pp. 1866-1890, 2014. DOI: 10.1007/s11367-014-0788-0.

[2] ISO, Environmental management—life cycle assessment — principles and framework, ISO 14040:2006, n.d.

[3] Berckmans, G., Messagie, M., Smekens, J., Omar, N., Vanhaverbeke, L. \& Van Mierlo, J., Cost projection of state of the art lithium-ion batteries for electric vehicles up to 2030. Energies, 10(9), p. 1314, 2017. DOI: 10.3390/en10091314.

[4] Gopalakrishnan, R. et al., A Comprehensive Study on Rechargeable Energy Storage Technologies. Journal of Electrochemical Energy Conversion and Storage, 13(4), p. 040801, 2017. DOI: 10.1115/1.4036000.

[5] Li, B., Gao, X., Li, J. \& Yuan, C., Life cycle environmental impact of high-capacity lithium ion battery with silicon nanowires anode for electric vehicles. Environmental Science \& Technology, 48(5), pp. 3047-3055, 2014. DOI: 10.1021/es4037786.

[6] Peters, J.F., Baumann, M., Zimmermann, B., Braun, J. \& Weil, M., The environmental impact of Li-Ion batteries and the role of key parameters - A review. Renewable and Sustainable Energy Reviews, 67, pp. 491-506, 2017. DOI: 10.1016/j.rser.2016.08.039.

[7] Ambrose, H. \& Kendall, A., Effects of battery chemistry and performance on the life cycle greenhouse gas intensity of electric mobility. Transportation Research Part D: Transport and Environment, 47, pp. 182-94, 2016. DOI: 10.1016/j.trd.2016.05.009.

[8] Ellingsen, L.A.W., Majeau-Bettez, G., Singh, B., Srivastava, A.K., Valøen, L.O. \& Strømman, A.H., Life cycle assessment of a lithium-ion battery vehicle pack. Journal of Industrial Ecology, 18(1), pp. 113-24, 2014. DOI: 10.1111/jiec.12072.

[9] Oliveira, L., Messagie, M., Rangaraju, S., Sanfelix, J., Rivas, M.H. \& Van Mierlo, J., Key issues of lithium-ion batteries-from resource depletion to environmental performance indicators. Journal of Cleaner Production, 108, pp. 354-362, 2015. DOI: 10.1016/j.jclepro.2015.06.021.

[10] Messagie, M., Boureima, F.S., Coosemans, T., Macharis, C. \& Van Mierlo, J., A range-based vehicle life cycle assessment incorporating variability in the 
environmental assessment of different vehicle technologies and fuels. Energies, 7(3), pp. 1467-1482, 2014. DOI: 10.3390/en7031467.

[11] Aguirre K. et al., Lifecycle Analysis Comparison of a Battery Electric Vehicle and a Conventional Gasoline Vehicle Kimberly Aguirre, 2012.

[12] Weidema, B.P. \& Wesnaes, M.S., Data quality management for life cycle inventoriesan example of using data quality indicators. Journal of Cleaner Production, 4(3-4), pp. 167-174, 1996. DOI: 10.1016/s0959-6526(96)00043-1.

[13] Placke, T., Kloepsch, R., Dühnen, S. \& Winter, M., Lithium ion, lithium metal, and alternative rechargeable battery technologies: The odyssey for high energy density. Journal of Solid State Electrochemistry, 21(7), pp. 1939-1964, 2017. DOI:10.1007/s10008-017-3610-7.

[14] Sanfélix, J., Multiregional Input-Output Life Cycle Analysis of a Battery Pack for Electric Vehicle Applications, VUBPRESS, 2015.

[15] European Commission, Critical raw materials factsheets, 2017. DOI: 10.2873/398823.

[16] Majeau-Bettez, G., Hawkins, T.R. \& StrØmman, A.H., Life cycle environmental assessment of lithium-ion and nickel metal hydride batteries for plug-in hybrid and battery electric vehicles. Environmental Science \& Technology, 45(10), pp. 45484554, 2011. DOI: 10.1021/es103607c.

[17] Figgemeier, E., Electrode composition comprising carbon nanotubes, electrochemical cell and method of making electrochemical cells. EP 3029759 A1, 2016.

[18] Jungbluth, N. et al., Life-cycle inventories-Photovoltaics. Swiss Cent Life Cycle Invent Dübendorf, $\mathrm{CH}, 2009$.

[19] Zackrisson, M., Avellán, L. \& Orlenius, J., Life cycle assessment of lithium-ion batteries for plug-in hybrid electric vehicles-Critical issues. Journal of Cleaner Production, 18(15), pp. 1519-1529, 2010. DOI: 10.1016/j.jclepro.2010.06.004.

[20] Deng, Y., Li, J., Li, T., Gao, X. \& Yuan, C., Life cycle assessment of lithium sulfur battery for electric vehicles. Journal of Power Sources, 343, pp. 284-295, 2017. DOI: 10.1016/j.jpowsour.2017.01.036.

[21] Benavides, P.T., Dai, Q., Sullivan, J.L., Kelly, J.C. \& Dunn, J.B., Material and Energy flows Associated with Select Metals in GREET2: Molybdenum, Platinum, Zinc, Nickel, Silicon, 2015. 